\title{
Incidence, types and outcomes of congenital anomalies in babies born at a public, tertiary hospital in South Africa
}

\author{
M M M Mayer, MMed, FCPaed; S C Velaphi, PhD \\ Department of Paediatrics, Faculty of Health Sciences, University of the Witwatersrand, Johannesburg, South Africa \\ Corresponding author: M M M Mayer (Mayernte1@gmail.com)
}

\begin{abstract}
Background. Limited information is available on the incidence of major congenital abnormalities (MCAs) in low- and middle-income countries (LMICs).

Objective. To determine the incidence and types of MCA and associated all-cause mortality from a facility with a large delivery service in an LMIC.

Methods. Births and neonatal admission registers of live inborn births between 1 January 2012 and 31 December 2013 at the Chris Hani Baragwanath Academic Hospital, South Africa, were reviewed for diagnosis of MCA.

Results. A total of 201 infants were admitted with a diagnosis of MCA, of which 114 were inborn. This translated to an incidence of 2.60 per 1000 live births. The cardiovascular (43.9\%), gastrointestinal (21\%), musculoskeletal (13.2\%) and central nervous system (12.3\%) were commonly affected systems. Most MCAs were single defects (75.4\%), followed by trisomies (19.3\%). A significant number of infants with trisomies were born to multigravid women older than 35 years $(p<0.001)$. A significant number of infants with single defects were preterm $(p<0.002)$ and of low birth weight $(p<0.002)$. One third $(34 \%)$ required surgical intervention before hospital discharge. All-cause mortality at hospital discharge was $20.2 \%$, with more deaths among patients with trisomy $13(50 \%)$ and trisomy 18 (40\%) compared with patients with single defects $(19.8 \%)$ or trisomy $21(7.8 \%)(p<0.05)$.

Conclusion. The incidence of MCAs found in this study is much lower than what has been reported from HICs but similar to findings from other LMICs. MCAs in LMIC settings are associated with high mortality rates.
\end{abstract}

S Afr J Child Health 2021;15(4):193-197. https://doi.org/10.7196/SAJCH.2021.v15i4.1810

Congenital anomalies - also commonly referred to as birth defects, congenital disorders, congenital malformations or congenital abnormalities - are conditions of prenatal origin that are diagnosed before, at or after birth. ${ }^{[1]}$ Major congenital anomalies generally have a negative impact on an infant's health, including developmental or survival outcome. ${ }^{[2]}$ They are also most likely to be associated with high social and financial demands on the family and healthcare system. Children with major congenital anomalies often have complex needs within the home setting. ${ }^{[3-5]}$ Globally, approximately 3.2 million children are born with congenital anomalies every year. These conditions are a major contributor to infant and under-5 mortality ${ }^{[6,7]}$ According to the World Health Organization, 17 - $42 \%$ of infant deaths are attributed to congenital anomalies. ${ }^{[8]}$ In South Africa (SA), congenital abnormalities are the fourth highest cause of neonatal mortality, accounting for $17.6 \%$ of all neonatal deaths. ${ }^{[5]}$

The incidence of major congenital anomalies in high-income countries (HICs) has been reported as 26.9 per 1000 live births for the period $2005-2009 .{ }^{[8]}$ However, there is a paucity of data on incidence and types of congenital anomalies and the subsequent outcome of neonates with these anomalies from low- and middleincome countries (LMICs). Although the incidence of congenital abnormalities in LMICs is likely similar to that in HICs, outcomes during the neonatal period may be different because of the difference in resource availability in the settings.

The aim of this study was to determine the incidence and types of congenital abnormalities in SA, as an LMIC, together with the outcomes of affected infants at the time of hospital discharge.

\section{Methods}

\section{Study design and setting}

This retrospective, descriptive study was conducted at the Chris Hani Baragwanath Academic Hospital (CHBAH), which is a public tertiary hospital in Johannesburg, SA. It is a major referral centre for neonates with congenital anomalies from local clinics and hospitals elsewhere in Gauteng and neighbouring provinces. At the time of the study, it was one of only two centres in southern Gauteng that offered tertiary and surgical services for neonates with congenital anomalies.

This hospital handles 22000 in-hospital births per year and offers secondary or tertiary healthcare to approximately 8000 births from community health centres or midwifery obstetric units in Soweto.

\section{Study population}

All live births at CHBAH from the period January 2012 - December 2013, with clinically apparent major congenital abnormalities and those subsequently diagnosed on investigative studies during the neonatal period, were eligible for inclusion in the study. Patients admitted to either medical or surgical neonatal wards were included.

\section{Data collection and analysis}

Hospital registers from labour and delivery rooms in medical and surgical neonatal wards were reviewed for documentation of a diagnosis of congenital anomalies. Hospital records of patients diagnosed with a congenital anomaly as documented in the 
registers were reviewed. Data were collected on maternal and infant characteristics, types of abnormality, need for surgical management, and outcome to hospital discharge.

Data were entered into a Excel spreadsheet (Microsoft Corp., USA) and then analysed using Statistica (v. 13.3; Dell, USA). Abnormalities were classified as either multiple or single. Cases of multiple abnormalities were subsequently grouped as being either syndromic/association or non-syndromic. For multiple abnormalities, the affected organ system was noted as the system with major abnormalities or for which the patient needed admission.

The analysis focused on inborn infants only. Categorical variables were described according to frequencies and percentages of the total cohort. Continuous variables were described using means and standard deviation (SD) (if normally distributed) or medians and ranges (if not normally distributed). Chi-squared $\left(\chi^{2}\right)$ and Fisher's exact tests, with a significance level of $p<0.05$, were used to compare characteristics and outcomes of neonates with trisomies and those who had single defects.

\section{Results}

\section{Incidence and types of anomalies}

Records of 201 neonates born with major congenital abnormalities were found for the study period, of whom 87 were referred from other facilities and 114 were inborn. With a total of 43876 in-hospital live births during the study period, the incidence of major congenital anomalies at CHBAH was 2.6 per 1000 live births. Of the 114 neonates with major congenital anomalies, 86 cases (75\%) presented with single defects and 28 cases (25\%) with multiple defects (Fig. 1). Among the 28 neonates with multiple defects, 22 had trisomies, three had associations and three had multiple anomalies that could not be allocated to a known syndrome (nonsyndromic).

\section{Maternal and infant characteristics}

Maternal and infant characteristics are presented in Table 1. Most of the infants $(n=107 ; 94.7 \%)$ were born to African mothers. The majority of mothers $(n / N=63 / 102 ; 61.7 \%)$ were between 20 and 35 years old. Two-thirds $(n=68 ; 66 \%)$ were multigravida and approximately three-quarters of the women whose HIV status was known were negative $(n=86 ; 74 \%)$. Just over half $(56 \%)$ of neonates were born by caesarean section. The mean (SD) birth weight of infants was 2530 (785) g. Of the 110 records, 58\% ( $n=64)$ showed low birth weight $(<2500 \mathrm{~g})$. The mean (SD) gestational age was 36 (3) weeks. Of the available records, $61 \%$ showed preterm births (gestational age $<37$ weeks). The proportion of male to female infants was even. Most abnormalities (>90\%) were diagnosed postdelivery.

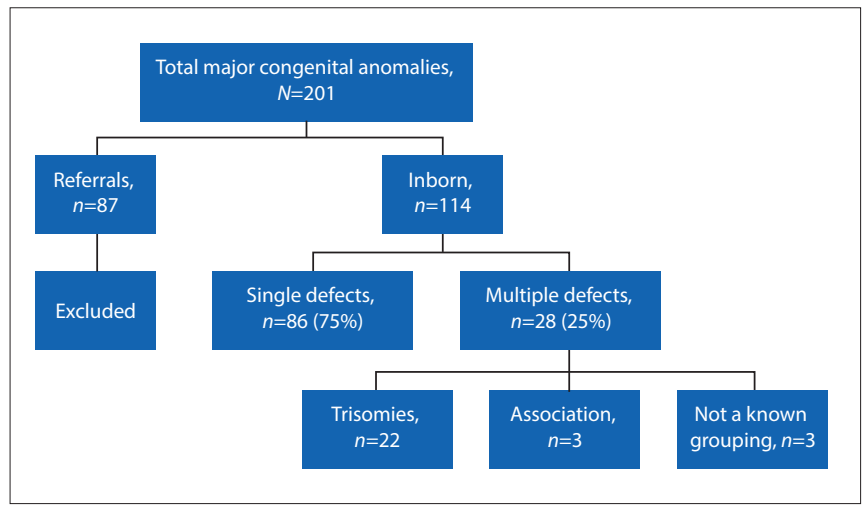

Fig. 1. Study population and major congenital anomalies identified.

\section{Organ systems affected by congenital anomalies}

Cardiovascular anomalies accounted for $43.9 \%$ of cases, followed by anomalies of the gastrointestinal (21\%), musculoskeletal (13.2\%) and central nervous systems (12.3\%) (Table 2). Among the cardiovascular anomalies, the majority were acyanotic (79\%), with ventricular septal defects and patent ductus arteriosus being the commonest; patent ductus arteriosus diagnosed in preterm infants was excluded. The most common gastrointestinal tract abnormalities were abdominal wall defects ( $n=11 / 24 ; 45.8 \%)$, with gastroschisis being more common than omphalocele, followed by tracheoesophageal fistula $(n=4 / 24$; $16.7 \%)$. Skeletal dysplasias $(n=6 / 15 ; 40 \%)$ and isolated cases of club foot $(n=3 / 15 ; 20 \%)$ were common musculoskeletal abnormalities. Common central nervous system abnormalities included congenital hydrocephalus $(n=5 / 14 ; 35.7 \%)$ and meningomyelocele $(n=5 / 14$; $35.7 \%$ ) (Table 3 ).

Table 1. Characteristics of mothers and their infants with congenital abnormalities

\begin{tabular}{|c|c|}
\hline Characteristics & $n(\%)$ \\
\hline \multicolumn{2}{|l|}{ Maternal characteristics } \\
\hline \multicolumn{2}{|l|}{ Maternal age (years), $N=102^{\star}$} \\
\hline$<20$ & $13(12.7)$ \\
\hline $20-35$ & $63(61.7)$ \\
\hline$>35$ & $26(25.6)$ \\
\hline \multicolumn{2}{|l|}{ Gravidity $(N=103)^{*}$} \\
\hline$<2$ & $35(34.0)$ \\
\hline $2-4$ & $59(57.3)$ \\
\hline$>4$ & $9(8.7)$ \\
\hline \multicolumn{2}{|l|}{ HIV status $(N=107)^{*}$} \\
\hline Positive & $28(26.2)$ \\
\hline Negative & $79(73.8)$ \\
\hline \multicolumn{2}{|l|}{ Mode of delivery $(N=105)^{\star}$} \\
\hline Vaginal delivery & $46(43.8)$ \\
\hline Caesarean section & $59(56.2)$ \\
\hline \multicolumn{2}{|l|}{ Antenatal care attendance $(N=114)$} \\
\hline Yes & $108(94.7)$ \\
\hline No & $6(5.3)$ \\
\hline \multicolumn{2}{|l|}{ Infant characteristics } \\
\hline Birth weight $(\mathrm{g})$, mean $(\mathrm{SD})(N=110)^{*}$ & $\begin{array}{l}2530 \\
(785)\end{array}$ \\
\hline Birth weight $>2500 \mathrm{~g}$ & $46(41.8)$ \\
\hline Birth weight $\leq 2500 \mathrm{~g}$ & $64(58.2)$ \\
\hline Gestational age (weeks), mean (SD) $(N=108)^{\star}$ & $36(3)$ \\
\hline$\geq 37$ & $42(38.9)$ \\
\hline$<37$ & $66(61.1)$ \\
\hline \multicolumn{2}{|l|}{$\operatorname{Sex}(N=114)$} \\
\hline Male & $55(48.2)$ \\
\hline Female & $56(49.1)$ \\
\hline Ambiguous & $3(2.6)$ \\
\hline \multicolumn{2}{|l|}{ Apgar score, median (range) $(N=110)^{*}$} \\
\hline At 1 minute & $8(1-9)$ \\
\hline At 5 minutes & $9(2-10)$ \\
\hline \multicolumn{2}{|l|}{ Period of diagnosis $(N=93)^{*}$} \\
\hline Antepartum & $9(9.7)$ \\
\hline Post partum & $84(90.3)$ \\
\hline
\end{tabular}




\section{Characteristics of infants with trisomies}

The maternal and infant characteristics of neonates with trisomies are noted in Table 4 . Of the 28 neonates with multiple congenital abnormalities, $22(20 \%)$ met the criteria for trisomies. Trisomy 21 was most commonly observed $(n=13 / 22 ; 59 \%)$, followed by trisomy $18(n=5 / 22 ; 23 \%)$ and trisomy $13(n=4 / 22 ; 18 \%)$. Infants who presented with trisomies were all born to multigravid women, most of whom were older than 35 years. Mean (SD) birth weight of infants with trisomy was 2452 (622) g, and mean (SD) gestational age was 37 (3) weeks. Of the 22 infants who presented with trisomies, $12(55 \%)$ were male. The majority of trisomy 21 patients had congenital cardiac defects $(n=10 / 13 ; 76.9 \%)$. The most common cardiac anomaly was atrioventricular septal defect, followed by atrial septal defect and patent ductus arteriosus.

\section{Outcomes to hospital discharge}

Approximately a third of the infants with congenital anomalies (34\%) required surgical intervention before hospital discharge (Table 5). Less than half required mechanical ventilator support (40\%). Overall survival to hospital discharge was 79.8\% (mortality rate $=20.2 \%$ ). There was no statistically significant difference in mortality rate according to need for surgery $(23.1 \%$ v. $21.2 \%$,

Table 2. Organ systems affected by congenital anomalies $(N=114)$

\begin{tabular}{llll}
\hline Affected system & $\boldsymbol{n}(\%)$ & $\begin{array}{l}\text { Incidence } \\
\text { (per 10 000 } \\
\text { live births) }\end{array}$ & $\begin{array}{l}\text { Incidence } \\
\text { (per 1 000 } \\
\text { live births) }\end{array}$ \\
\hline Cardiovascular & $50(43.9)$ & 11.4 & 1.14 \\
Gastrointestinal & $24(21.1)$ & 5.5 & 0.55 \\
Musculoskeletal & $15(13.2)$ & 3.4 & 0.34 \\
Central nervous system & $14(12.3)$ & 3.2 & 0.32 \\
Urogenital & $13(11.4)$ & 3.0 & 0.30 \\
Head and neck & $13(11.4)$ & 3.0 & 0.30 \\
Respiratory & $5(4.4)$ & 1.1 & 0.11 \\
Skin & $3(2.6)$ & 0.7 & 0.07 \\
Total & $137^{*}$ & 26 & 2.6 \\
*In some patients, more than one organ system was affected, hence the total \\
number of anomalies exceeds the total number of patients (114).
\end{tabular}

$p=0.821)$ or mechanical ventilation $(28.3 \%$ v. $15.4 \%, p=0.110)$ compared with those who did not need these interventions. Common causes of mortality were healthcare-associated infections, mainly in those who required surgical intervention, and severe or complex congenital anomalies that could not be corrected or were inoperable. Of the 13 cases of trisomy 21 , two patients required mechanical ventilation, of whom one died following Gram-negative sepsis. Two deaths occurred in the trisomy 18 group (not related to sepsis); the other three patients survived to hospital discharge. Two of the four patients who presented with trisomy 13 died, both from sepsis.

\section{Comparison between neonates with trisomies and those with single defects}

There were 22 patients with trisomies and 86 with single defects (Table 6), with more infants born to mothers of advanced age ( $>35$ years) in the group with trisomies than the group with single defects $(63.6 \%$ v. $11.6 \%$; $p<0.001)$. All trisomy infants were born to multigravid women, whereas $59.3 \%$ of women whose infants presented with single defects had had previous pregnancies $(p<0.001)$. More infants with single defects were of low birth weight $(<2500 \mathrm{~g})$ or born preterm ( $<37$ weeks' gestational age) compared with those who presented with trisomy (for both categories: $74.4 \%$ v $36.4 \% ; p=0.002$ ). There were no statistically significant differences in maternal HIV status, infant sex, need for surgery, or mortality between infants with trisomies and those with single defects.

\section{Discussion}

This study was a retrospective record review to investigate the incidence and types of major congenital anomalies and the associated all-cause mortality from a hospital in an LMIC. The study showed an incidence of 2.6 congenital abnormalities per 1000 live births at a public tertiary hospital in Gauteng, SA. The majority of babies with congenital abnormalities were born preterm and were of low birth weight. The cardiovascular and gastrointestinal systems were the most commonly affected. Single defects accounted for the majority of congenital abnormalities. Most patients who presented with multiple defects had trisomies. About a third of neonates with major congenital abnormalities required corrective interventions before hospital discharge. A fifth demised before

Table 3. Specific diagnosis in systems commonly affected by congenital anomalies

\begin{tabular}{|c|c|c|c|c|c|c|c|}
\hline \multicolumn{2}{|c|}{$\begin{array}{l}\text { Cardiovascular } \\
(N=53), n(\%)\end{array}$} & \multicolumn{2}{|c|}{$\begin{array}{l}\text { Gastrointestinal } \\
(N=24), n(\%)\end{array}$} & \multicolumn{2}{|c|}{$\begin{array}{l}\text { Musculoskeletal } \\
(N=15), n(\%)\end{array}$} & \multicolumn{2}{|c|}{$\begin{array}{l}\text { Central nervous system } \\
(N=14), n(\%)\end{array}$} \\
\hline Acyanotic & $42(79.2)$ & Gastroschisis & $7(29.2)$ & $\begin{array}{l}\text { Skeletal } \\
\text { dysplasia }\end{array}$ & $6(40)$ & $\begin{array}{l}\text { Congenital } \\
\text { hydrocephalus }\end{array}$ & $5(35.7)$ \\
\hline $\begin{array}{l}\text { Ventricular septal } \\
\text { defect }\end{array}$ & $14(33)$ & Omphalocele & $4(16.7)$ & Club foot & $3(20)$ & Meningomyelocele & $5(35.7)$ \\
\hline $\begin{array}{l}\text { Patent ductus } \\
\text { arteriosus }\end{array}$ & $15(35.7)$ & $\begin{array}{l}\text { Tracheoesophageal } \\
\text { fistula }\end{array}$ & $4(16.7)$ & Myopathy & $2(13.3)$ & Encephalocele & $2(14.3)$ \\
\hline $\begin{array}{l}\text { Atrial septal } \\
\text { defect }\end{array}$ & $9(21.4)$ & $\begin{array}{l}\text { Anorectal } \\
\text { malformation }\end{array}$ & $3(12.5)$ & $\begin{array}{l}\text { Abnormal } \\
\text { vertebrae }\end{array}$ & $2(13.3)$ & Microcephaly & $1(7.1)$ \\
\hline $\begin{array}{l}\text { Atrioventricular } \\
\text { septal defect }\end{array}$ & (7.1) & Duodenal atresia & $3(12.5)$ & Hip dysplasia & $1(6.7)$ & Anencephaly & $1(7.1)$ \\
\hline Coarctation of aorta & $1(2.4)$ & Jejunal atresia & $2(8.3)$ & Knee dislocation & $1(6.7)$ & & \\
\hline Cyanotic & $11(20.8)$ & Others & $1(4.2)$ & & & & \\
\hline $\begin{array}{l}\text { Double outlet right } \\
\text { ventricle }\end{array}$ & $3(27)$ & & & & & & \\
\hline Tetralogy of Fallot & $2(18.2)$ & & & & & & \\
\hline Pulmonary atresia & $2(18.2)$ & & & & & & \\
\hline Others & $4(36.4)$ & & & & & & \\
\hline
\end{tabular}


Table 4. Characteristics of mothers of infants with trisomies

\begin{tabular}{|c|c|c|c|c|}
\hline Characteristics & $\begin{array}{l}\text { All } \\
(N=22), \\
n(\%)\end{array}$ & $\begin{array}{l}\text { Trisomy } \\
21(N=13), \\
n(\%)\end{array}$ & $\begin{array}{l}\text { Trisomy } \\
18(N=5), \\
n(\%)\end{array}$ & $\begin{array}{l}\text { Trisomy } \\
13(N=4), \\
n(\%)\end{array}$ \\
\hline \multicolumn{5}{|c|}{ Maternal age (years) } \\
\hline$<20$ & 0 & 0 & 0 & 0 \\
\hline $20-35$ & $8(36.4)$ & $5(38.5)$ & $2(40.0)$ & $1(25.0)$ \\
\hline$>35$ & $14(63.6)$ & $8(61.5)$ & $3(60.0)$ & $3(75.0)$ \\
\hline \multicolumn{5}{|l|}{ Gravidity } \\
\hline Primigravida & 0 & 0 & 0 & 0 \\
\hline Multigravida & $22(100)$ & $13(100)$ & $5(100)$ & $4(100)$ \\
\hline \multicolumn{5}{|l|}{ Mode of delivery } \\
\hline $\begin{array}{l}\text { Caesarean } \\
\text { section }\end{array}$ & $6(27.3)$ & $5(38.5)$ & 0 & $1(25.0)$ \\
\hline $\begin{array}{l}\text { Vaginal } \\
\text { delivery }\end{array}$ & $16(72.7)$ & $8(61.5)$ & $5(100)$ & $3(75.0)$ \\
\hline \multicolumn{5}{|l|}{ HIV status } \\
\hline Negative & $16(72.7)$ & $10(76.9)$ & $3(60.0)$ & $3(75.0)$ \\
\hline Positive & $6(27.3)$ & $3(23.1)$ & $2(40.0)$ & $1(25.0)$ \\
\hline \multicolumn{5}{|l|}{ Antenatal care } \\
\hline Yes & $22(100)$ & $13(100)$ & $5(100)$ & $4(100)$ \\
\hline No & 0 & 0 & 0 & 0 \\
\hline
\end{tabular}

Table 5. Survival to hospital discharge according to type of abnormality and intervention

\begin{tabular}{ll}
\hline Patient group & $\begin{array}{l}\text { Deaths, } \\
n(\%)\end{array}$ \\
\hline All patients $(N=114)$ & $23(20.2)$ \\
Survival according to abnormalities & \\
Trisomy $21(N=13)$ & $1(7.7)$ \\
Trisomy18 $(N=5)$ & $2(40.0)$ \\
Trisomy13 $(N=4)$ & $2(50.0)$ \\
Non-syndromic $(N=3)$ & $1(33.3)$ \\
Association $(N=3)$ & $0(0)$ \\
Single-defects $(N=86)$ & $17(19.8)$ \\
Survival according to need for neonatal surgical intervention \\
Surgery required $(N=39)$ & $9(23.1)$ \\
Surgery not required $(N=66)$ & $14(21.2)$ \\
Survival according to need for mechanical ventilation & \\
Ventilated $(N=46)$ & $13(28.3)$ \\
Not ventilated $(N=65)$ & $10(15.4)$
\end{tabular}

hospital discharge, with the major cause of death being healthcareassociated infections.

The incidence of congenital abnormalities found in this study is similar to that reported from Nigeria (2.8 per 1000 live births), also an LMIC. ${ }^{[4]}$ It is ten times lower than the incidence of 26.9 per 1000 live births reported from an $\mathrm{HIC},{ }^{[9]}$ likely owing to better surveillance systems and data registries typically being in place in developed countries than in LMICs. ${ }^{[10]}$ Given the retrospective design of the current study, it is possible that some infants with major congenital anomalies but who were not recorded in the registries could have been missed. In contrast, surveillance for congenital abnormalities in HICs includes antenatal ultrasound examinations, which would allow for early detection of abnormalities and consequently better documentation.

The review suggests that the opportunity to detect congenital anomalies in utero was missed in this cohort, as although most

\begin{tabular}{|c|c|c|c|}
\hline Characteristic & $\begin{array}{l}\text { Trisomies } \\
(N=22), n(\%)\end{array}$ & $\begin{array}{l}\text { Single defect } \\
(N=86), n(\%)\end{array}$ & $p$-value \\
\hline \multicolumn{4}{|c|}{ Maternal age (years) } \\
\hline$<20$ & 0 & $13(15.1)$ & \multirow{3}{*}{$<0.001$} \\
\hline $20-35$ & $8(36.4)$ & $63(73.3)$ & \\
\hline$>35$ & $14(63.6)$ & $10(11.6)$ & \\
\hline \multicolumn{4}{|l|}{ Gravidity } \\
\hline Primigravida & 0 & $35(40.7)$ & \multirow{2}{*}{$<0.001$} \\
\hline Multigravida & $22(100)$ & $51(59.3)$ & \\
\hline \multicolumn{4}{|l|}{ HIV status } \\
\hline Positive & $6(27.3)$ & $28(32.6)$ & \multirow{2}{*}{0.798} \\
\hline Negative & $16(72.7)$ & $58(67.4)$ & \\
\hline \multicolumn{4}{|l|}{$\operatorname{Sex}^{*}$} \\
\hline Female & $10(45.5)$ & $42(50.6)$ & \multirow{2}{*}{0.811} \\
\hline Male & $12(54.5)$ & $41(49.4)$ & \\
\hline \multicolumn{4}{|l|}{ Birth weight (g) } \\
\hline$<2500$ & $8(36.4)$ & $64(74.4)$ & \multirow{2}{*}{0.002} \\
\hline$\geq 2500$ & $14(63.6)$ & $22(25.6)$ & \\
\hline \multicolumn{4}{|c|}{ Gestational age (weeks) } \\
\hline$<37$ & $8(36.4)$ & $64(74.4)$ & \multirow{2}{*}{0.002} \\
\hline$\geq 37$ & $14(63.6)$ & $22(25.6)$ & \\
\hline \multicolumn{4}{|c|}{ Need for surgical intervention } \\
\hline Yes & $4(18.2)$ & $35(40.7)$ & \multirow{2}{*}{0.080} \\
\hline No & $18(81.8)$ & $51(59.3)$ & \\
\hline \multicolumn{4}{|c|}{ Survival to hospital discharge } \\
\hline Yes & $17(77.3)$ & $69(80.2)$ & \multirow{2}{*}{0.771} \\
\hline No & $5(22.7)$ & $17(19.7)$ & \\
\hline
\end{tabular}

women in the study (90\%) attended antenatal care, only $10 \%$ had a diagnosis made in the antenatal period. In addition, stillbirths were not included in this study. It is possible that the small number of anomalies detected in utero is due to antenatal sonar examinations not having been offered routinely to all pregnant women during the study period. Excluding stillbirths and data on termination of pregnancy for fetal anomalies leads to the burden of disease due to congenital anomalies being underestimated, obscuring the lack of progress with regard to primary, secondary and tertiary prevention measures and programmes.

The incidence of central nervous system anomalies in this study was 3.2 per 10000 live births, which is much lower than what has been reported from three other studies in SA..$^{[5,11,12]}$. The most recent of these, conducted in 2004 - 2005, reported an incidence of 9.8 per 10000 live births. ${ }^{[5]}$ The difference in the incidence rates may be due to regional variation in this type of abnormality. Globally, the incidence of neural tube defects varies greatly, with estimates ranging from 1.2 to 124.1 per 10000 live births. ${ }^{[13]}$

In SA, staple foods such as maize and wheat products are fortified with folic acid. ${ }^{[6,14,15]}$ Fortification has had a major effect in reducing central nervous system abnormalities in other countries. ${ }^{[9,16]}$ However, as the current study reviewed a small set of data from a single centre, it is difficult to know whether fortification contributed to the low incidence of neural tube defects.

Surgical intervention is an important but unheralded component of the services required to treat birth defects. Many of these are cost-effective, life-saving interventions that can improve long- 
term prognosis. In LMICs, where resources are typically limited, the availability of surgical services and access to intensive care beds might result in delays in offering children with congenital abnormalities the necessary interventions. Sepsis was a major contributor to mortality, highlighting the importance of reducing hospital stay of these patients and observing infection control measures in managing these patients while awaiting surgery.

The mortality rate found in the current study (20\%) is higher than that reported in a study from Nigeria (10\%), ${ }^{[17]}$ and much higher than a rate of $1.13 \%$ in Italy (an HIC). ${ }^{[18]}$ The higher mortality rate seen in the current study may be ascribed to only major congenital anomalies having been included, whereas the two other studies ${ }^{[17,18]}$ included all congenital anomalies, including minor cases such as inguinal hernias, hypospadias and genu recurvatum.

Congenital anomalies are a considerable health problem throughout the world. Knowledge of their incidence, intervention requirements and outcomes can assist in planning and expectant management of infants with major anomalies as well as management of affected pregnancies. As the aetiology of some conditions may be elusive and multifactorial, continued surveillance is important in identifying causal or preventive factors associated with the development of major congenital anomalies. ${ }^{[19,20]}$

\section{Study limitations}

Incomplete data introduce a limitation in a retrospective study design and complicate identifying factors that might have been associated with the incidence and outcomes of congenital anomalies. Possible risk factors, such as outcomes of previous pregnancies (previous abortions or presence of congenital anomalies), maternal illness and drugs used before or during pregnancy were often not recorded, and as such prospective data collection would be a more effective approach in a study of this kind.

\section{Conclusion}

The incidence of congenital anomalies found in this study is lower than what has been reported from HICs, but is likely an underestimation of the true incidence in our population. The findings suggest that more efforts should be directed at early identification and registration of congenital abnormalities to allow for better understanding of the burden of congenital anomalies and improve healthcare planning and management of patients, possibly reducing mortality. Collaboration between major centres that offer tertiary and surgical services to children with congenital abnormalities might assist in establishing a sentinel site surveillance system. The development of efficient provincial or national registries and population-based studies in public health settings in LMICs is important to determine the incidence and types of congenital abnormality accurately. Accurate data can contribute to identifying possible aetiological factors in the development of congenital abnormalities, which, in turn, may help to prevent them.

\section{Declaration. XX.}

Acknowledgements. We thank the patients and staff of the neonatal unit at the Department of Paediatrics at CHBAH.

Author contributions. MMM was responsible for conceptualising the research, data collection and analysis, and preparing the manuscript. SV contributed to study conceptualisation and data analysis, and reviewed the manuscript for submission.

\section{Funding. None.}

Conflicts of interest. None.

1. Hovels-Gurich H. [Psychomotor and cognitive development and quality of life in children and adolescents with congenital heart defect]. Klinische Padiatrie 2019;231(4):183-190. https://doi.org/10.1055/a-0942-1756

2. Dingemann C, Sonne M, Ure B, Bohnhorst B, von Kaisenberg C, Pirr S. Impact of maternal education on the outcome of newborns requiring surgery for congenital malformations. PLoS One 2019;14(4):e0214967. https://doi. org/10.1371/journal.pone.0214967

3. Gatt M, England K, Grech V, Calleja N. Contribution of congenital anomalies to neonatal mortality rates in Malta. Paediatr Perinat Epidemiol 2015;29(5):401406. http://doi.org/10.1111/ppe.12206

4. Obu HA, Chinawa JM, Uleanya ND, Adimora GN, Obi IE. Congenital malformations among newborns admitted in the neonatal unit of a tertiary hospital in Enugu, South-East Nigeria - a retrospective study. BMC Res Notes 2012;5:177. https://doi.org/10.1186/1756-0500-5-177

5. Sayed AR, Bourne D, Pattinson R, Nixon J, Henderson B. Decline in the prevalence of neural tube defects following folic acid fortification and its costbenefit in South Africa. Birth Defects Res A Clin Mol Teratol 2008;82(4):211216. https://doi.org/10.1002/bdra.20442

6. Centeno Tablante E, Pachon H, Guetterman HM, Finkelstein JL. Fortification of wheat and maize flour with folic acid for population health outcomes. Cochrane Database Syst Rev 2019;7:Cd012150. https://doi.org/10.1002/14651858. CD012150.pub2

7. Malherbe HL, Christianson AL, Woods D, Aldous C. Under-5 mortality and the contribution of congenital disorders in South Africa. S Afr Med J 2018;108(6):447-448. https://doi.org/10.7196/SAMJ.2018.v108i6.13331

8. Boyle B, Addor MC, Arriola L, et al. Estimating Global Burden of Disease due to congenital anomaly: An analysis of European data. Arch Dis Child Fetal Neonatal Ed 2018;103(1):F22-F28. https://doi.org/10.1136/ archdischild-2016-311845

9. Castillo-Lancellotti C, Tur JA, Uauy R. Impact of folic acid fortification of flour on neural tube defects: A systematic review. Public Health Nutr 2013;16(5):901911. https://doi.org/10.1017/s1368980012003576

10. Moorthie S, Blencowe H, Darlison MW, et al. Estimating the birth prevalence and pregnancy outcomes of congenital malformations worldwide. J Community Genet 2018;9(4):387-396. https://doi.org/10.1007/s12687-018-0384-2

11. Buccimazza SS, Molteno CD, Dunne TT, Viljoen DL. Prevalence of neural tube defects in Cape Town, South Africa. Teratology 1994;50(3):194-199.

12. Venter PA, Christianson AL, Hutamo CM, Makhura MP, Gericke GS Congenital anomalies in rural black South African neonates - a silent epidemic? S Afr Med J 1995;85(1):15-20.

13. Zaganjor I, Sekkarie A, Tsang BL, et al. Describing the prevalence of neural tube defects worldwide: A systematic literature review. PLoS ONE 2016;11(4):e0151586. https://doi.org/10.1371/journal.pone.0151586

14. Harika R, Faber M, Samuel F, Kimiywe J, Mulugeta A, Eilander A. Micronutrient status and dietary intake of iron, vitamin a, iodine, folate and zinc in women of reproductive age and pregnant women in Ethiopia, Kenya, Nigeria and South Africa: A systematic review of data from 2005 to 2015. Nutrients 2017;9(10):1096. https://doi.org/10.3390/nu9101096

15. Atta CA, Fiest KM, Frolkis AD, et al. Global birth prevalence of spina bifida by folic acid fortification status: A systematic review and meta-analysis. Am J Public Health 2016;106(1):e24-34. https://doi.org/10.2105/ajph.2015.302902

16. Richard-Tremblay AA, Sheehy O, Berard A. Annual trends in use of periconceptional folic acid and birth prevalence of major congenital malformations. Curr Drug Saf 2013;8(3):153-161.

17. Ajao AE, Adeoye IA. Prevalence, risk factors and outcome of congenital anomalies among neonatal admissions in OGBOMOSO, Nigeria. BMC Pediatr 2019;19(1):88. https://doi.org/10.1186/s12887-019-1471-1

18. Groen H, Bouman K, Pierini A, et al. Stillbirth and neonatal mortality in pregnancies complicated by major congenital anomalies: Findings from a large European cohort. Prenat Diagn 2017;37(11):1100-1111. https://doi. org/10.1002/pd.5148

19. Sallout B, Obedat N, Shakeel F, Mansoor A, Walker M, Al-Badr A. Prevalence of major congenital anomalies at King Fahad Medical City in Saudi Arabia: A tertiary care centre-based study. Ann Saudi Med 2015;35(5):343-351. https:// doi.org/10.5144/0256-4947.2015.343

20. Toufaily MH, Westgate MN, Lin AE, Holmes LB. Causes of congenital malformations. Birth Defects Res 2018;110(2):87-91. https://doi.org/10.1002/ bdr2.1105

Accepted 12 January 2021. 